\title{
Avaliação da linguagem em crianças com deficiência intelectual no contexto de escolarização formal
}

\author{
Assessment of language in children with intellectual disabilities in the context \\ of formal schooling
}

Evaluación del lenguaje en los niños con discapacidad intelectual en el contexto de escolarización formal

\author{
Adelyn Barbosa de Aquino \\ Mestra pela Universidade Federal de Pernambuco, Recife, Pernambuco, Brasil. \\ adelynaquino7@gmail.com \\ ORCID - https://orcid.org/0000-0001-6808-4667
}

\author{
Tícia Cassiany Ferro Cavalcante \\ Professora doutora na Universidade Federal de Pernambuco, Recife, Pernambuco, Brasil. \\ ticiaferro@hotmail.com \\ ORCID - https://orcid.org/0000-0001-8963-9609
}

Recebido em 27 de agosto de 2019

Aprovado em 11 de março de 2020

Publicado em 10 de abril de 2020

\section{RESUMO}

As crianças com deficiência intelectual, que por muito tempo foram estigmatizadas em relação à aprendizagem, apresentam prejuízo no desenvolvimento da capacidade expressiva, principalmente na expressão oral. Por isso, fazem uso por mais tempo da linguagem gestual. Esta pesquisa buscou analisar as habilidades comunicativas das crianças com deficiência intelectual na etapa da Educação Infantil. Para tanto, tomou-se como base teórica o sociointeracionismo, concebendo a linguagem como um construto social resultado de trocas interativas. Como sujeitos, a pesquisa contou com a participação de duas crianças com deficiência intelectual com impedimentos comunicativos, estudantes de escolas públicas da cidade de Igarassu-PE. Como instrumentos de coleta de dados realizou-se entrevistas com profissionais da escola e pais; também observações da sala de aula; e uma sessão de intervenção com o uso de recursos de Comunicação Alternativa. Foi possível perceber que a comunicação com as crianças muitas vezes é realizada através de gestos, bem como da importância de se conhecer a dinâmica de vida de cada criança, para que se trace um plano de comunicação. Com os resultados do presente estudo pode-se pensar em diretrizes para uma comunicação mais efetiva dos estudantes com deficiência intelectual no contexto da educação infantil.

Palavras-chave: Inclusão escolar; aquisição da linguagem; deficiência intelectual.

\section{ABSTRACT}

Children with intellectual disabilities, who have long been stigmatized in relation to learning, present impairment in the development of expressive capacity, especially in oral expression. Therefore, they make use of sign language for longer. This research aimed to analyze the communicative abilities of children with intellectual disabilities in the stage of Early 
http://dx.doi.org/10.5902/1984686X39773

Childhood Education. For that, the socio-interactionism was taken as theoretical basis, conceiving language as a social construct resulting from interactive exchanges. As subjects, the research had the participation of two children with intellectual disabilities with communicative disabilities, students of public schools in the city of Igarassu-PE. As data collection instruments, interviews were conducted with professionals from the school and parents; also observations of the classroom; and an intervention session with the use of Alternative Communication resources. It was possible to perceive that communication with children is often performed through gestures, as well as the importance of knowing the dynamics of life of each child, so that a communication plan is drawn up. With the results of the present study we can think of guidelines for a more effective communication of students with intellectual disabilities in the context of early childhood education.

Keywords: School inclusion; acquisition of language; intellectual disability.

\section{RESUMEN}

Los niños con discapacidad intelectual, que durante mucho tiempo fueron estigmatizados en relación al aprendizaje, presentan perjuicio en el desarrollo de la capacidad expresiva, principalmente en la expresión oral. Por eso, hacen uso por más tiempo del lenguaje de signos. Esta investigación buscó analizar las habilidades comunicativas de los niños con discapacidad intelectual en la etapa de la Educación infantil. Para ello, se tomó como base teórica el sociointeracionismo, concebiendo el lenguaje como un constructo social resultado de intercambios interactivos. Como sujetos, la investigación contó con la participación de dos niños con discapacidad intelectual con impedimentos comunicativos, estudiantes de escuelas públicas de la ciudad de Igarassu-PE. Como instrumentos de recolección de datos se realizaron entrevistas con profesionales de la escuela y padres; también observaciones del aula; y una sesión de intervención con el uso de recursos de Comunicación Alternativa. Es posible percibir que la comunicación con los niños muchas veces se realiza a través de gestos, así como de la importancia de conocer la dinámica de vida de cada niño, para que se trace un plan de comunicación. Con los resultados del presente estudio se puede pensar en directrices para una comunicación más efectiva de los estudiantes con discapacidad intelectual en el contexto de la educación infantil.

Palabras clave: Inclusión escolar; adquisición del lenguaje; deficiencia intelectual.

\section{Introdução}

Esta pesquisa tem como foco o processo de aquisição da língua materna, especificamente, a investigação acerca da aquisição da linguagem por crianças com impedimentos comunicativos, em consequência da deficiência intelectual. Buscou-se debruçar não por uma vertente inatista dos estudos da aquisição da linguagem, em que se acredita que a linguagem é resultado apenas de aparatos biológicos herdados pela criança; também não caminharemos numa vertente empirista, em que se acredita que a experiência com a língua e o treinamento que recebemos quando criança são suficientes para a aquisição da linguagem. Conceberemos aqui a língua como um construto histórico, resultado de práticas sociocomunicativas. 
http://dx.doi.org/10.5902/1984686X39773

Nesse sentido, a interação social e a troca comunicativa entre as crianças e seus interlocutores são vistas como pré-requisito básico no desenvolvimento linguístico; "rituais comunicativos pré-verbais preparam e precedem a construção da linguagem pela criança" (SCARPA, 2001, p. 214).

Para Luria, a linguagem é a capacidade humana de compreender e utilizar um sistema dinâmico e complexo de símbolos convencionados em modalidades diversas para pensar e se comunicar; é uma habilidade complexa desde os tempos mais remotos (no sentido filogenético), se aprimorando numa velocidade constante no intuito de melhorar cada vez mais a comunicação entre as pessoas e o meio que the cerca (LURIA, 1987).

Luria (1987) acreditava que a interação humana é a propulsora dos processos de construção da significação, sendo que a linguagem, por integrar a estrutura dos processos cognitivos, encarrega-se de regular e mediar toda atividade psíquica. Para o autor, a estruturação da consciência do homem é formada pela palavra, que é, fundamentalmente, o elemento que caracteriza nossa ação de pensar e nos permite expressar nossas relações e experiências e, também, constitui a base do pensamento abstrato. Portanto:

o elemento fundamental da linguagem é a palavra. A palavra designa as coisas, individualiza suas características. Designa ações, relações, reúne objetos em determinados sistemas. Dito de outra forma, a palavra codifica nossa experiência (LURIA, 1987, p. 27).

Luria (1987) entende a palavra como um instrumento regulador dos processos psíquicos superiores, permitindo ao homem alcançar um nível abstrato de pensamento. Entende que a palavra tem a função de representar um objeto, de substituí-lo na ausência da experiência. Porém, antes de adquirir essa noção, para a criança inicialmente, a palavra possui um caráter simpráxico, em que ela não é compreendida de forma autônoma em si, mas depende de meios que a signifiquem, como a entonação, os gestos e as circunstancias. Portanto, o sentido e o valor só são compreendidos em contexto específico, sendo incapaz de associar a palavra fora do contexto imediato que está vivendo. Nesse sentido, a palavra ou balbucios exprimem uma necessidade, podendo a criança utilizar a mesma palavra para designar objetos diferentes. A partir das mediações a criança vai significando a palavra para, posteriormente, adquirir a função social dessa palavra.

A aquisição da linguagem não deve ser concebida como um processo mecânico de memorização, mas o oposto, pois é um processo intelectual complexo e dinâmico que deriva do contato da criança com o meio social. Trata-se de um processo histórico-cultural, processo em que a criança aprende os símbolos linguísticos cultural e socialmente 
http://dx.doi.org/10.5902/1984686X39773

compartilhados a partir de experiências de interação com o adulto. "Portanto, comunicar implicará uma reorganização de representações sociais, culturais e mentais que, por meio da linguagem como instrumento de comunicação e psicológico (signo), permite a construção e a partilha de significados" (PASSERINO; BEZ, 2015, p 21-22).

Todavia, de acordo com Nunes (2003), cerca de uma entre duzentas pessoas é incapaz de comunicar-se através da fala devido a fatores neurológicos, físicos, emocionais e cognitivos. Fazem parte dessa população as crianças com deficiência intelectual, foco do artigo aqui reportado.

A terminologia deficiência intelectual substituiu o ultrapassado termo deficiência mental. De acordo com Santos (2012), o termo deficiência mental causava confusão com a doença mental, sendo que esta consiste em um transtorno psicológico.

A deficiência intelectual é caracterizada por uma maior limitação no uso dos recursos cognitivos e em pelo menos duas habilidades relacionadas à vida diária, o que envolve habilidades como comunicação, cuidados pessoais, habilidades sociais, desempenho na família e na comunidade, independência, saúde, segurança, desempenho escolar, trabalho e lazer (FUJIHIRA, 2012).

A deficiência intelectual pode causar falhas na memória auditiva de curto prazo; dificuldades com a linguagem/fala; dificuldades sensoriais com a audição e visão; dificuldade em generalizar e atraso na coordenação motora grossa e fina (ANHÃO; PFEIFER; SANTOS, 2010).

De acordo com Santos (2012), a característica fundamental da deficiência intelectual é o significativo prejuízo cognitivo.

As funções cognitivas correspondem à capacidade de aprender e compreender, sendo funções superiores que se estabelecem a partir do sistema nervoso central. Elas englobam as capacidades de linguagem, aquisição da informação, percepção, memória, raciocínio, pensamento etc., as quais permitem a realização de tarefas como leitura, escrita, cálculos, conceptualização, sequência de movimentos, dentre outras (SANTOS, 2012, p. 938).

Para Cavalcante e Ferreira (2011), a deficiência intelectual não é uma condição estática, tão pouco um traço pessoal. Nesse sentido, a pessoa com deficiência intelectual não deve ser vista apenas pelos impedimentos. Deve-se considerar o funcionamento da pessoa na interação com o mundo, atentando as oportunidades e auxílios recebidos ao longo da vida. Dessa forma, escolas com práticas homogeneizadoras, com apenas uma metodologia de ensino apoiada nas crianças sem deficiência, acabam por acentuar a 
http://dx.doi.org/10.5902/1984686X39773

deficiência, agravando as dificuldades de acesso ao conhecimento do estudante com deficiência intelectual.

Para Santos (2012), o prejuízo cognitivo da criança com deficiência intelectual, dentre outros fatores, causa prejuízo no desenvolvimento da capacidade expressiva do indivíduo, principalmente a expressão oral. Das crianças com deficiência intelectual que aprendem a falar, boa parte, produz apenas frases curtas e simples. Esse déficit na produção da linguagem causa dificuldades na interação da criança, pois como as pessoas não entendem muito bem o relato daqueles que tem deficiência intelectual acabam por não insistir em falar e a criança, ao participar de poucas oportunidades de interação, não evolui na linguagem (SANTOS, 2012).

Segundo Duarte e Velloso (2017), uma característica importante da linguagem dessa população é a diferença existente entre sua capacidade de compreensão e de expressão. A dificuldade é frequentemente maior na produção de linguagem, ou seja, na expressão. As pessoas com DI sempre apresentam atraso na aquisição e desenvolvimento da linguagem, variando os prejuízos apresentados de indivíduo para indivíduo, assim como o grau de comprometimento. Conforme os referidos autores, as pessoas com deficiência intelectual apresentam condição semelhante a uma construção inacabada, sendo que sua evolução é similar à de pessoas com desenvolvimento típico mais novas. Da mesma forma, o déficit de comunicação da pessoa com DI caracteriza-se por um desvio lento, e segue as mesmas etapas que o da criança sem atraso, mas não completando essas etapas de maneira adequada e na idade esperada.

Fujihira (2012) alerta que, mesmo com todos os impedimentos, a deficiência intelectual não é uma doença e sim uma condição muito peculiar de compreender e apreender as situações.

Se a forma de compreender é diferente, a maneira de estar no mundo também fica "configurada" de forma diferente. É uma maneira de existir, não uma doença. De fato há uma dificuldade nesta condição, em absorver muitas informações rapidamente - tanto no raciocínio abstrato quanto na autonomia em certos aspectos da vida cotidiana. Mas isso não significa impossibilidade de compreensão e participação. Há formas mais acessíveis de se apresentar apoios e informações que possibilitem um entendimento (FUJIHIRA, 2012, p. $54)$.

De acordo como Cavalcante (2017), a comunicação pode favorecer bastante a aprendizagem por ser um instrumento psicológico superior de origem social, ou seja, capaz de modificar as estruturas psicológicas. Para isso, é necessário considerar todas as possibilidades de comunicação, como: as verbalizações - construções de frases verticais 
http://dx.doi.org/10.5902/1984686X39773

(um só elemento) ou com construções horizontais (mais de um elemento); e os gestos representativos (que sinalizam) da comunicação - podem ser formados por apontar, olhar, expressão facial, dentre outros, bem como pelo auxílio de símbolos gráficos.

Entender que cada criança se desenvolve de maneira singular, com deficiência ou não, é que entender que as leis de desenvolvimento são iguais para todas as pessoas, e que apenas os caminhos para o desenvolvimento são diferentes. Assim, o olhar que se deve ter para a pessoa com deficiência intelectual não é o do defeito, para aquilo que falta, mas para aquilo que se tem em potencial. Sobre isso a teoria socio-histórica do desenvolvimento de Vygoski traz grandes contribuições (VYGOTSKI, 1997; 2001).

\section{Metodologia}

Teve como campo de pesquisa duas escolas municipais da cidade de Igarassu, cidade da região metropolitana do Recife-Pernambuco: uma escola de Educação Infantil na zona urbana e uma escola na zona rural da cidade. A escolha das escolas se deu por contato com a secretaria de educação municipal.

Foram considerados sujeitos com perfil de pesquisa as crianças com deficiência intelectual cursando a Educação Infantil que tivessem algum impedimento comunicativo. As duas crianças selecionadas adotaram nomes fictícios de Ana e Laura.

Nas duas escolas contatadas foram identificadas três crianças com diagnóstico de deficiência intelectual e uma com Síndrome de Down, que também apresenta deficiência intelectual. Duas das crianças, um menino com Síndrome de Down e uma menina diagnosticada com deficiência intelectual, tinham linguagem oral fluente, não apresentava impedimentos comunicativos, por isso não foram selecionados como sujeito de pesquisa. As duas crianças selecionadas adotaram nomes fictícios de Ana e Laura.

Além das crianças, os pais, professores e uma auxiliar de uma das crianças também foram participantes da pesquisa.

A coleta de dados seguiu três etapas: entrevista, observação em sala de aula regular e uma sessão de intervenção com as crianças individualmente, com uso de recursos de comunicação alternativa. O termo Comunicação Alternativa é utilizado para definir outras formas de comunicação como o uso de gestos, sinais da língua de sinais, expressões faciais, o uso de pranchas de alfabeto ou símbolos pictográficos, comunicadores, até o uso de sistemas sofisticados como o computador com voz sintetizada e tablets (SARTORETTO; BERSCH, 2014; REILY, 2004). 
http://dx.doi.org/10.5902/1984686X39773

A utilização de instrumentos de coleta como entrevistas semiestruturadas e observações na sala de aula, é mais importante que o uso de testes, pois permitem a avaliação das competências da pessoa no contexto de suas vidas cotidianas, abrangendo áreas como o nível de autonomia pessoal, as competências sociais, os problemas de comportamento e a comunicação (TETZCHNER; MARTISEN, 2000). A partir do cruzamento das informações obtidas com esses instrumentos e do resultado da primeira sessão de intervenção foram criados os perfis das crianças, constando: identificação; rotina e comportamento; parceiros de comunicação; atendimentos profissionais; e habilidades comunicativas (verbal e/ou não verbal).

\section{Entrevistas com pais e professores}

Trata-se de uma anamnese, em que buscamos através dos relatos dos pais e responsáveis, das psicopedagogas do Atendimento Educacional Especializado, das professoras da sala de aula regular e de uma auxiliar de sala, além de conhecer um pouco da história de vida e contexto social em que as crianças estão inseridas, identificar as necessidades e potencialidades comunicativas. Para Tetzchner e Martisen (2000), as informações dadas pelos pais e pelos profissionais da escola com contato diário com a criança serão a fonte de informação importante sobre as várias formas de comunicação utilizadas pela criança. Os roteiros das entrevistas foram adaptações do protocolo de avaliação das habilidades comunicativas de alunos não falantes em situação escolar e familiar, elaborados respectivamente por De Paula (2007) e Delagracia (2007). Nesses roteiros, foram abordadas questões como: aspectos subjetivos da criança (de socialização e estado emocional); centro de interesses; rotina; terapias e outros atendimentos realizados pelas crianças. Outros aspectos centrais questionados foram relativos às habilidades comunicativas da criança, como: uso da fala; de gestos; habilidades de compreensão e de expressão (se pela fala ou por gestos); uso de expressões faciais. Um ponto importante é que algumas crianças com deficiência fazem uso da fala, mesmo que usando apenas uma palavra; procurou-se entender que tipos de recursos comunicativos as crianças fazem uso.

\section{Observação da sala de aula}

Conforme Tetzchner e Martisen (2000), a observação sistemática é sempre uma parte importante da avaliação de uma pessoa, seja qual for o tipo de deficiência que possua. Portanto, é importante observar a pessoa em situações e atividades diversas, tanto quando 
http://dx.doi.org/10.5902/1984686X39773

está só, como acompanhada. Para compreender melhor 0 contexto de comunicação/interação das crianças com as professoras e colegas na sala de aula foram realizadas observações da rotina de sala de aula. Da rotina escolar de Ana (primeiro sujeito), observou-se um mês e meio, período que correspondeu aos meses de junho e julho de 2017. Já da rotina de Laura (segundo sujeito) realizou-se um mês de observações, mês de outubro de 2017. As observações foram feitas duas vezes por semana em tempo integral, 4 horas/aula, incluindo intervalos (lanche e recreio). Para registro das observações utilizou-se como instrumentos um diário de campo. O roteiro de observação teve o objetivo de registrar os momentos de interação entre a criança com impedimento de fala e seus pares e professores, identificando gestos e palavras que utilizam para se comunicar.

\section{Sessão de intervenção}

A intervenção tratou-se de momentos de interações, com o uso de recursos de comunicação alternativa, entre a pesquisadora e as crianças, individualmente, a partir de atividades de linguagem oral típicas da Educação Infantil, como contação de histórias, músicas, conversas, entre outras.

Foram realizadas oito sessões de intervenção com Ana e seis intervenções individuais com Laura. As sessões com Ana aconteceram na sala de AEE (Atendimento Educacional Especializado) e com Laura, aconteceram no terraço da escola. Para esse estudo, utilizamos apenas a primeira sessão de intervenção de Ana e a primeira sessão de intervenção de Laura, que tiveram o caráter mais avaliativo, as demais sessões demarcaram outros objetivos de pesquisa, a exemplo do papel desempenhado pela Comunicação Alternativa no processo comunicacional dessas crianças.

O planejamento das intervenções sempre contava com a colaboração das professoras da sala de aula regular. Para organização das intervenções, uma semana antes de cada sessão, era combinado com a professora o tema das intervenções, que era sempre de acordo com seu planejamento da semana. As primeiras intervenções, tanto de Laura quanto de Ana, foram realizadas com base na contação de história, em que foram realizadas adequações das histórias com o uso de recursos de comunicação alternativa do tipo pictográfico, como no exemplo a seguir: 
http://dx.doi.org/10.5902/1984686X39773

Figura 1 - Recursos de comunicação alternativa produzidos para as intervenções

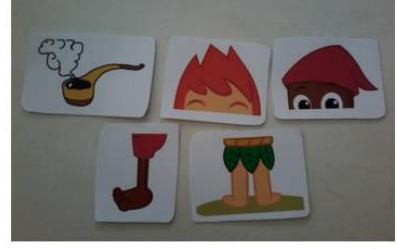

(A)

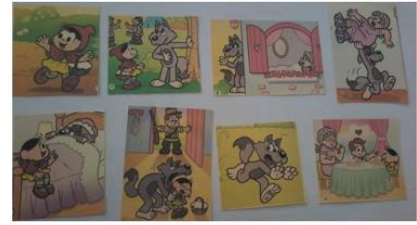

(B)

Legenda: A) Cartões B) Cartões com sequência de ilustrações Fonte: elaboração das autoras (2019).

Os dados gerados pelas intervenções foram coletados a partir de videografias. O uso desse instrumento de observação amplifica a capacidade de análise, já que possibilita ao observador repensar o observado (VIANNA, 2003; BERGAMASCO, 1996).

\section{Análise dos dados}

Os dados foram analisados a partir de uma abordagem teórico-metodológica sociointeracionita, concebendo a língua como uma construção histórica, resultado de práticas sociocomunicativas; e entendendo a aquisição da linguagem como um processo pelo qual a criança se coloca como sujeito da linguagem aprendendo sobre o mundo na interação com o outro (SCARPA, 2001).

Utilizou-se para a análise alguns conceitos desenvolvidos por Vigotsky (1997), sendo este um dos principais teóricos da abordagem sociointeracionista. Os dados foram analisados à luz de conceitos de deficiência, concebida não como um déficit centrado no impedimento orgânico dos sujeitos, mas como a falta de oportunidades sociais para que esses sujeitos se desenvolvam.

Congregando da mesma abordagem socio-histórica, a análise se baseia também nas discussões de Luria (1987) sobre a aquisição da linguagem entendendo a linguagem como signo que modifica as funções psicológicas superiores, tendo a função de mediar e regular o contato do sujeito com o mundo na troca de experiência com outros sujeitos.

As entrevistas dos familiares e professoras, as observações da sala de aula registradas em diário de campo e as transcrições das sessões de intervenção foram analisadas por análise do conteúdo, Bardin (2009). Os resultados da avaliação das habilidades comunicativas estão apresentados e discutidos por meio de trechos das transcrições das entrevistas, anotações do diário de campo e transcrições das intervenções. A partir do cruzamento dos dados dos dois primeiros instrumentos e das 
http://dx.doi.org/10.5902/1984686X39773

primeiras seções de intervenção foram elaboradas as categorias para a análise das habilidades comunicativas das crianças: 1. Identificação da criança; 2. Rotina e comportamento; 3. Parceiros comunicativos; 4. Atendimento profissional; e 5. Habilidades comunicativas, classificadas como: verbal e não verbal.

\section{Análise e discussão do corpus}

\section{Perfil comunicativo das crianças}

Esta seção tem a intenção de apresentar os sujeitos participantes da pesquisa e diagnosticar suas habilidades de fala, identificando necessidades e potencialidades. Um diagnóstico de linguagem tem o objetivo de explorar todo o desenvolvimento da compreensão e expressão do indivíduo, levando-se em conta a linguagem antes da fala propriamente dita (DUARTE; VELLOSO, 2017). Porém, não seria legítimo falar em habilidades comunicativas do sujeito sem levar em consideração o meio em que vive e os parceiros com quem interage. Na busca por habilidades comunicativas, se faz necessário observar como o ambiente e os parceiros de comunicação contribuem para a formação da competência comunicativa da criança.

Conforme Deliberato (2013) e Manzini e Deliberato (2004), a avaliação do meio em que o aluno com impedimento comunicativo vive é tão importante quanto à avaliação apenas do indivíduo, pois quando se foca apenas na criança faz com que os problemas e as limitações fiquem centrados nela, deixando de lado o que o ambiente pode oferecer ou não para o desenvolvimento de suas habilidades comunicativas, e o que poderia ser feito para melhorar ou adequar o ambiente. Tetzchener e Martinsen (2000) alertam para o fato da avaliação incluir não só situações de ensino, mas também sobre o uso da linguagem em casa e em outros contextos.

Após estruturação e organização das informações foram identificas as unidades significativas de análise (BARDIN, 2009). As unidades são descritas no Quadro 1.

Quadro 1 - Unidades para avaliação das habilidades comunicativas

\begin{tabular}{|l|l|}
\hline \multicolumn{1}{|c|}{ Unidades } & \multicolumn{1}{c|}{ Descrição } \\
\hline Identificação das crianças & Diagnóstico, gênero, idade, escola e turma. \\
\hline Rotina e Comportamento & Participação nas diversas atividades na sala de aula. \\
\hline Parceiros de comunicação & Qualidade das interações. \\
\hline Atendimento profissional & Dentro e fora da escola. \\
\hline Habilidades comunicativas & Habilidades expressivas verbais e não verbais. \\
\hline
\end{tabular}

Fonte: Elaboração própria (2018). 
http://dx.doi.org/10.5902/1984686X39773

\section{Identificação das crianças}

A primeira criança será referenciada a partir de agora pelo nome fictício de Ana. Responderam as entrevistas sobre ela: a professora regular, a psicopedagoga do AEE e o pai. Trata-se de uma menina de cinco anos diagnosticada com deficiência Intelectual. Estuda em uma escola urbana de Educação Infantil do município de Igarassu, turma Infantil B, turno da tarde.

Já a segunda criança adotará o nome fictício de Laura. As entrevistas foram respondidas pela mãe, professora regular, auxiliar da sala e a psicopedagoga do AEE. A criança é uma menina de quatro anos também diagnosticada com deficiência Intelectual leve. Estuda em uma escola rural e de difícil acesso do município de Igarassu, turma Infantil A, turno da manhã. As duas crianças estudam em sala regular.

\section{Rotina e comportamento}

O ambiente escolar é fundamental ao desenvolvimento de habilidades comunicativas, pois nele o indivíduo pode socializar-se com outras pessoas além dos familiares, bem como compartilhar conhecimentos e aprender novas formas de comunicação. A interação social entre o aluno com deficiência e as pessoas da escola é fundamental para as questões pedagógicas (DELIBERATO, 2017). Sendo a Educação Infantil a primeira etapa de escolarização, torna-se a primeira oportunidade da criança interagir com interlocutores diferentes dos familiares. Observar o comportamento das crianças com déficit na linguagem, durante a rotina pedagógica, nesta fase de ensino, faz-se necessário para compreender se, e como, o ambiente da sala de aula oportuniza que a criança se expresse e tenha acesso ao conhecimento.

Quando questionada sobre o comportamento de Ana na sala de aula, a professora lhe caracterizou como um pouco agitada e tendo dificuldades em seguir regras, também relatou que a criança participa pouco das atividades propostas o que pode ser comprovado durante as observações. Na rotina pedagógica as atividades iniciais eram, na maioria das vezes, de estímulo à linguagem oral como roda de conversa, músicas e contação de histórias. Nesses momentos, a criança não se mostrava muito participativa. Muitas vezes, ficava sentada na cadeira enquanto os colegas formavam rodas.

Os momentos de maior participação de Ana se davam quando a professora buscava estimulá-la. Quando, por exemplo, a professora a convidou para participar como um dos personagens no reconto da história. O segundo momento da aula era de exposição dos 
http://dx.doi.org/10.5902/1984686X39773

conteúdos e tarefas escritas. Esse era um momento de menos interação e, algumas vezes, Ana parecia não demonstrar interesse ao que era exposto, não prestava atenção e até se negava a realizar a tarefa. Esse tipo de comportamento pouco participativo pode estar associado à frustração de não ser compreendida. A dificuldade de expressar-se pode influenciar diretamente na participação e interação durante as atividades pedagógicas.

Dentre as atividades de rotina da sala de aula, o momento em que Ana conseguia interagir melhor com os colegas era a hora do lanche. As crianças prestavam mais atenção ao que Ana queria comunicar neste momento. O exemplo 1 traz um trecho das anotações do diário de campo.

Exemplo 1 - contexto: No horário do lanche as crianças se reúnem para dividir como em um piquenique.

\begin{abstract}
Uma das crianças da turma (C1) teve dificuldade de abrir o refrigerante, Ana fez um gesto de abrir, se oferecendo para ajudar a colega. A colega agradece. Minutos depois um dos colegas (C2) estava prestes a jogar a garrafinha de refrigerante no lixo, Ana acena com um não e com expressão de desagrado e em seguida aponta para um saco em cima da estante cheio de garrafinhas que seriam utilizadas em atividade em outro momento. A criança (C2) compreende os gestos de Ana e realiza a ação.
\end{abstract}

Laura, a segunda criança, apresenta comportamento semelhante ao de Ana. Das atividades pedagógicas demonstra mais interesse nos momentos de leitura e música, porém, não se concentra por muito tempo. Sobre a rotina na sala de aula, durante as observações as atividades eram, na maior parte das vezes, individuais. As crianças eram chamadas uma por vez para responder tarefas pela professora; enquanto isso, as outras brincavam com brinquedos ou manuseavam livros de historinhas.

A professora da sala regular caracteriza o comportamento de Laura como muito inquieta e às vezes agressiva. Durante o período de observações notou-se que a criança, em alguns momentos, intimidava os colegas, tomando brinquedos ou atrapalhando as brincadeiras, também não costumava ser convidada a brincar em grupo.

Exemplo 2 - contexto: Enquanto a professora e a auxiliar estão realizando atividades individualizadas com algumas crianças, outras brincam ou conversam em grupos.

Estão reunidas um grupo de meninas (C1, C2 e C3), C1 mostra uma toalha nova com uma personagem de desenho animado que trouxe de casa, as outras meninas (C2 e C3) pedem para segurar e conversam sobre a personagem, Laura olha a cena de longe, chega na mesa sorrindo e estende a mão para pegar a toalha, as meninas parecem não perceber o pedido de Laura que irritada toma a toalha e corre. As meninas $(C 1, C 2$ e $C 3)$ reclamam com a professora que toma e devolve a toalha a $\mathrm{C} 1$. 
http://dx.doi.org/10.5902/1984686X39773

De Paula (2007); Manzini e Deliberato (2004) alertam que até mesmo problemas de comportamento podem estar associados a impedimentos na comunicação, já que seria uma forma mais imatura da criança chamar atenção. No caso de Laura, seu comportamento demonstra dificuldade de se relacionar socialmente, ou seja, dificuldade em estabelecer e manter relações a partir da linguagem.

As análises das rotinas e comportamento das crianças tiveram muitos pontos em comum. Ambas eram consideradas pelas professoras da sala de aula regular como crianças com comportamentos difíceis e ambas demonstraram, durante as observações, pouca participação nas atividades propostas. É possível então considerar que o ambiente escolar das duas crianças, Ana e Laura, na maioria das vezes, não colaboravam para que as mesmas tivessem oportunidades comunicativas; poucas foram as estratégias de mediação que as professoras ou colegas utilizaram para que as crianças tivessem condições de interagir melhor e participar de maneira mais ativa das atividades pedagógicas.

\section{Parceiros de comunicação:}

Para Manzini e Deliberato (2004) e Nunes (2003) é necessário atenção aos diferentes parceiros de comunicação em cada ambiente. É preciso observar as oportunidades de comunicação que eles oferecem ao indivíduo não falante e o modo como interagem, pois a principal característica das dificuldades de comunicação dos indivíduos não falantes é a baixa expectativa que seus parceiros têm em relação à sua capacidade de veicular novas informações e produzir mensagens complexas. Para Cavalcante (2017), muitas vezes, as pessoas com deficiência intelectual são subestimadas pelas pessoas com que convivem por associarem o impedimento da comunicação com a impossibilidade de aprender e se desenvolver. Dessa forma, não oferecem condições de aprendizagem e desenvolvimento para a criança, que, como qualquer outra, precisa de estimulação precoce.

Ana tem como principais parceiros de comunicação os irmãos, primos e as colegas de sala, conforme relataram o pai e a professora na entrevista. Foi observado durante as aulas que em alguns momentos, como a realização das tarefas ou trabalhos em grupo, os colegas não prestavam muita atenção ao que a criança queria expor por não compreender sua fala e seus gestos ou por acreditaram que a criança não era capaz de se comunicar. Podemos usar como exemplo um trecho do diário de campo em que uma das colegas se surpreende com o fato de Ana conseguir se comunicar. 
http://dx.doi.org/10.5902/1984686X39773

Exemplo 3 - Contexto: A professora solicitou que as crianças fizessem um trabalho de corte e colagem sobre suas famílias.

\begin{abstract}
As crianças utilizam revistas e livros para escolher figuras que representem seus familiares, depois colam em uma folha de ofício. Ao fim dos trabalhos, a professora chama um aluno de cada vez para apresentar sua produção. Ana apresenta para a turma sua família, conta com a ajuda da professora que perguntava pelos familiares enquanto a criança apontava quem eram na colagem e, mesmo com dificuldade, conseguiu pronunciar as palavras: papai e vovó, nesse momento uma das colegas se mostra surpresa e fala: "Olha, ela sabe falar!".
\end{abstract}

Os parceiros de comunicação de Laura também eram os familiares e colegas de sala. Diferente de Ana, Laura, conseguia se expressar através da fala, porém, algumas vezes, não conseguia manter diálogos com os colegas, como relatado anteriormente no trecho do diário de campo no exemplo 2. Laura tem dificuldade de interagir com os colegas e por não ser compreendida, às vezes, é agressiva. Segundo Duarte e Velloso (2017), os indivíduos com deficiência intelectual tem dificuldade em utilizar a linguagem para interação social, como cumprimentar, saber esperar pela sua vez na conversação, ser capaz de captar a atenção de seus parceiros de comunicação através de estratégias não verbais, como contato visual ou toque, e verbais, como iniciar, manter e terminar um diálogo, fazer modificações semânticas e sintáticas, dependendo da pessoa a quem se dirige e diversificar a utilização de várias funções comunicativas.

\title{
Atendimento profissional
}

Todos os profissionais que atendem as crianças na escola foram entrevistados, um dos objetivos da entrevista foi entender como os profissionais atuam diante do impedimento de fala da criança, ou seja, como acontece a mediação da linguagem.

Sobre os profissionais que lhe assiste, além da professora da sala regular, Ana tem encontros com a psicopedagoga da sala de atendimento educacional. Não há outro profissional de apoio na sala de aula, apenas a professora. Já Laura, além da professora regular, conta com uma auxiliar na sala de aula e, também é assistida pela psicopedagoga do AEE. Laura também não tem atendimentos com outros profissionais fora da escola.

Sabe-se que o ideal é que o atendimento educacional especializado seja realizado em contra turno da sala regular para garantir que a criança com deficiência possa participar de todas as atividades pedagógica, porém, conforme Lourenço (2017) a uma diversidade em como os municípios tem organizado o atendimento na sala de recursos, se acontecem em contra turno ou mesmo turno da aula regular; frequência dos alunos por semana; tempo de 
http://dx.doi.org/10.5902/1984686X39773

duração do atendimento, se individualizado ou em pequenos grupos; organização da sala; os recursos de tecnologia assistiva, entre outras questões, dependem das condições das secretarias de Educação. No caso das escolas de Ana e Laura, os atendimentos acontecem duas vezes por semana, de maneira individual, com o tempo de uma hora aula. Acontecem no mesmo horário de aula, ou seja, em alguns momentos as crianças deixam a sala de aula para serem atendidas na sala de recursos.

Quando perguntada sobre o trabalho com Ana, a psicopedagoga relatou que tem realizado intervenções na sala de recursos para ampliar sua comunicação, a criança tem aprendido a Língua de sinais. Durante as observações foi possível perceber a criança fazendo uso de alguns sinais da Libras (Língua Brasileira de Sinais) o que, nesse caso, não seria o prioritário já que a criança não é surda. Já a psicopedagoga que acompanha Laura na Sala do AEE relatou que tem trabalhado com jogos para estimular a linguagem da criança, um dos jogos que mostrou foi a caixa de imagens em que pedia para que a criança retirasse algumas imagens e falasse sobre elas espontaneamente.

\section{Habilidades comunicativas:}

Uma característica importante da linguagem de crianças com Deficiência Intelectual é a diferença existente entre sua capacidade de compreensão e de expressão que, nesse caso, a dificuldade é frequentemente maior na produção de linguagem, ou seja, na expressão. (CAVALCANTE, 2011; DUARTE; VELLOSO, 2017). Neste trabalho, a análise das habilidades comunicativa teve como base as habilidades expressivas que podem ser classificadas como verbais e não verbais. É preciso salientar que este trabalho parte do pressuposto de que tanto a fala (habilidades expressivas verbais) quanto os gestos (habilidades expressivas não verbais) são atividades cognitivas, instrumentos de interação social.

Sobre as habilidades de comunicação de Ana, os entrevistados divergiram nas respostas. A professora regular afirmou que a criança parece não entender o que ela fala, pois, às vezes, não atende quando the pede algo. Já a professora do AEE e o pai afirmam que a criança compreende quando falam com ela. A psicopedagoga utiliza gestos como apoio para a comunicação e ensina para a criança alguns sinais da Libras. Ana utiliza fala para se comunicar, porém, a fala não é funcional; é com o uso de gestos e expressões faciais que consegue se expressar melhor. Sua linguagem oral é de poucas e curtas palavras, mesmo assim, pronuncia com dificuldade. Para Manzini e Deliberato (2004), 
http://dx.doi.org/10.5902/1984686X39773

durante a avaliação da linguagem é importante observar os diferentes meios comunicativos utilizados pelas crianças com deficiência além da linguagem oral.

Laura possui linguagem oral, consegue expressar suas necessidades e desejos verbalmente, porém, na maioria das vezes, produz frases com apenas uma palavra para se comunicar. Também, segundo a mãe e a professora regular, há momentos em que ela apresenta dificuldade em manter um diálogo com adultos por se distrair com facilidade, e muitas vezes, responde a perguntas apenas com o gesto de balançar a cabeça. Conforme Duarte e Velloso (2017), na D.I. é comum o déficit na produção da linguagem, com alterações na morfologia e, em decorrência disso, há a construção de frases curtas e simples. Devido ao impedimento na capacidade expressiva podem ocorrem poucas interações diárias que favoreçam o aperfeiçoamento da linguagem, o que acaba gerando um ciclo: como as pessoas não entendem muito bem o relato daquele indivíduo com DI, ele não insiste na fala, sendo que a linguagem e a fala são elementos primordiais para o melhor desenvolvimento dos demais processos cognitivos.

\section{Habilidades expressivas não verbais}

Foram consideradas expressões não verbais utilizadas pelas crianças, as gesticulações, olhares, expressões faciais e até o uso da língua de sinais - Libras. O uso de gestos são características de uma fase inicial da linguagem. Quando as crianças vão adquirindo a fala, vão diminuindo o uso de gestos para se comunicar, embora fala e gestos nunca se dissociem totalmente (VYGOTSKI, 2001).

Tanto nas observações como nas intervenções Ana se expressou mais com o uso dos gestos do que com uso da fala. Utilizou gestos com diferentes funções: para responder, fazer escolhas, fazer perguntas, contar um fato, dizer o que pensa e o que sente. No exemplo 4, trecho da transcrição da primeira intervenção, a criança utiliza gestos durante o diálogo com a pesquisadora.

Quadro 2 - Sinais e legenda das transcrições

\begin{tabular}{|l|l|}
\hline SINAL & LEGENDA \\
\hline Pesq. & Pesquisadora \\
\hline Crian. & Criança \\
\hline T & Turno de fala* \\
\hline Ana e Laura & Nomes fictícios das crianças sujeitos de pesquisa. \\
\hline C1, C2, C3, etc. & Demais crianças - Colegas de sala de aula. \\
\hline
\end{tabular}


http://dx.doi.org/10.5902/1984686X39773

Quadro 2 - Sinais e legenda das transcrições

\begin{tabular}{|l|l|}
\hline SINAL & LEGENDA \\
\hline()$^{*}$ & $\begin{array}{l}\text { Para as descrições do contexto da realização das atividades } \\
\text { utilizou-se anotações entre parêntese. }\end{array}$ \\
\hline$(())^{*}$ & $\begin{array}{l}\text { Para as descrições das ações dos sujeitos utilizou-se anotações } \\
\text { entre parênteses duplos. }\end{array}$ \\
\hline$(\ldots)^{*}$ & $\begin{array}{l}\text { Para informar pausa na fala utilizou-se três pontos entre } \\
\text { parênteses. }\end{array}$ \\
\hline
\end{tabular}

Fonte: elaboração das autoras, (2019) baseadas na obra Análise da Conversação (MARCUSCHI, 2000).

Exemplo 4 - Contexto: A pesquisadora ler um livro de literatura infantil sobre o folclore.

Pesq. (T23): Aí o saci fez assim: Cuca, quer brincar comigo? Eu brinco, mas tem que chamar (...) o Boitatá!

((Ana faz um gesto com a língua imitando uma cobra))

Pesq. (T24): é uma cobra de fogo! Tu tem medo?

((Ana agora faz um gesto com a mão de serpenteado))

Pesq. (T53): A iara é essa aqui, é? A sereia?

((Ana pega o cartão da iara))

Ana (T54): Aqui, tia! ((Fala com dificuldade))

Pesq. (T55): Ela é linda e tem um rabo de peixe.

((Ana tenta falar algo com dificuldade e também usa gestos, coloca as duas mãos no peito como se fosse mostrar o biquíni da iara))

Pesq. (T56): É um biquíni? Ela tem um biquíni?

((Ana faz o gesto de amarrar o biquíni atrás, depois encena colocar as alças do biquíni e faz gesto de mergulho com as mãos)).

Ana (T57): Eu (...) Vitória. ((Fala com dificuldade))

Pesq. (T58): Tu fosse com Vitória para praia? Igual a uma sereia?

((Ana balança a cabeça em sinal positivo, depois tenta falar algo, mas é incompreensível. Faz uso de gestos de vestir-se))

Pesq. (T59): Tu vestiu uma calda de sereia, foi?

((Ana levanta-se e faz gesto de mergulho))

Pesq. (T60): Mergulhou? ((Risos)) Muito bom, Ana! Você é uma sereia igual a iara.

No exemplo, Ana faz o uso de gestos com a intenção de chamar a atenção da pesquisadora para características das personagens da história, para isso imita seus movimentos. No outro trecho chama a atenção da pesquisadora, com os gestos de vestir o biquíni e de mergulho, para o fato de ter ido à praia e de ter entrado no mar, se Ana e a pesquisadora não estivessem inseridas em um contexto de conversa, se não 
compartilhassem o sentido dos gestos, dificilmente esses gestos isolados seriam compreendidos. Nesses exemplos Ana utiliza os gestos com a função de simular ações, Cavalcante (2008) denomina essa função como pantomima, que tem como algumas das características a ausência de fala e estrutura não convencional, ou seja, a interpretação do interlocutor precisa de um contexto específico. A criança também utiliza os gestos com funções culturais, como os gestos de balançar a cabeça para afirmar ou negar algo; e alguns sinais da Língua Brasileira de Sinais, como as letras do alfabeto manual. Em quase todas às vezes os gestos de Ana não acompanhavam fala.

Já Laura faz pouco uso dos gestos. Para se comunicar utilizava, na maioria das vezes, frases curtas. Dos gestos utilizou mais os de função cultural como acenar com a cabeça como no exemplo 5, trecho da transcrição da primeira intervenção.

Exemplo 5 - contexto: A pesquisadora conta a história da Chapeuzinho Vermelho a partir de livro.

Pesq. (T1): Olha, Laura! Já ouvisse essa historinha aqui? ((Mostra a capa do livro Chapeuzinho Vermelho)).

((Laura balança a cabeça em sinal positivo)).

Pesq. (T2): Conhece essa menina com esse chapéu vermelho aqui? Sabe como é o nome dela?

((Laura balança a cabeça positivamente, porém, não fala o nome da personagem)).

Cavalcante (2008) caracteriza esse tipo de gesto, de confirmar ou negar com um balançar a cabeça como emblemático. Esses são gestos culturais, ou seja, o significado dos gestos pode ser compartilhado socialmente, podem ser compreendidos pelos interlocutores em diferentes situações. Laura também utilizou gestos na função de gesticulação, que são os que acompanham o fluxo da fala, como movimentos com os braços, de cabeça, de pernas, expressões faciais, etc.

\section{Habilidades Expressivas verbais}

Faz parte do processo evolutivo de aquisição da linguagem que o uso de gestos diminua e aos poucos seja substituído pelo símbolo, a fala convencional. A fala pode ser definida como toda forma de produção discursiva para fins comunicativos na modalidade oral que usa a língua na forma de sons articulados e significativos (MARCUSCHI, 2000). As crianças, sujeitos desta pesquisa, apresentaram etapas diferentes de produção da fala. 
http://dx.doi.org/10.5902/1984686X39773

Como já mencionado, para se comunicar Ana quase não utiliza fala, quando produz é de difícil compreensão. Os exemplos 6 e 7 trazem trechos de transcrições de intervenções em que a criança tenta se comunicar a partir da fala.

Exemplo 6 - Contexto: Início da seção de intervenção, a criança e a pesquisadora acabaram de chegar à sala de recursos para começar as atividades, uma das colegas chama Ana na porta.

\author{
Pesquisadora (T1): Vamos lá, Ana? \\ Criança (T2): Tia, tia, tia \\ Pesq. (T3): Oi? \\ Crian. (T4): Ali (...) ((fala incompreensível)) ((Aponta para porta)) \\ Pesq. (T5): Alguém te chamou, foi? Mas tu vai agora escutar a historinha que \\ tia trouxe. Tu quer escutar? Olha o livrinho ((Mostra a capa do livro)) vamos \\ ouvir a história desse livrinho, bora?
}

Exemplo 7 - Contexto: Depois da leitura Ana e a pesquisadora folheiam um livro de histórias sobre os personagens do folclore.

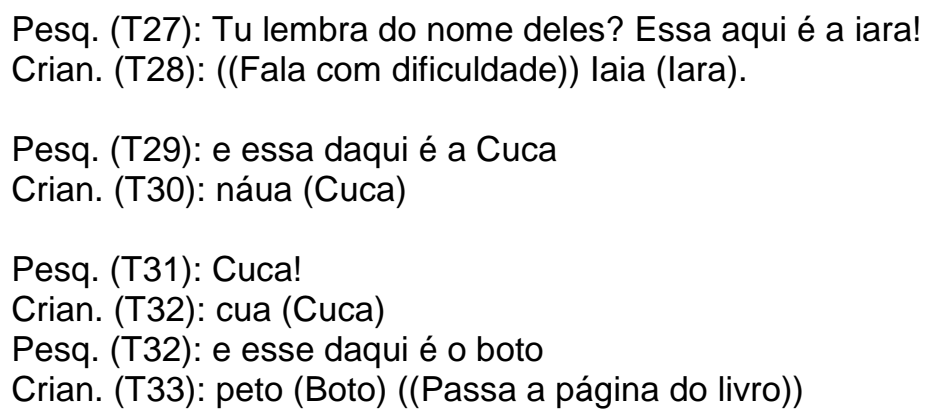

No exemplo 6, Ana pronuncia as palavras tia e ali, ainda tenta falar algo, mas a fala é incompreensível. Já no exemplo 7 Ana balbucia algumas palavras ditas pela pesquisadora, mas é pouco compreensível. A fala produzida por Ana é de frases horizontais, ou seja, frases de apenas uma palavra.

Já Laura, consegue produzir frases completas, porém, realiza poucas iniciativas de fala, na maioria das vezes, responde a perguntas com apenas uma palavra. Os exemplos 8 e 9 são trechos de transcrição da primeira intervenção.

Exemplo 8 - Contexto: A criança interrompe a leitura da historinha e chama a atenção da pesquisa a um parque instalado na praça em frente à escola.

Crian. (T4): Eu "foi" pro parque.

Pesq. (T5): Tu foi pro parque? No parque daqui? Andasse de quê?

Crian. (T6): Barco! 
http://dx.doi.org/10.5902/1984686X39773

Exemplo 9 - Contexto: Atividade sobre a história do Chapeuzinho Vermelho, colocar na cesta da Chapeuzinho comidas para a vovó.

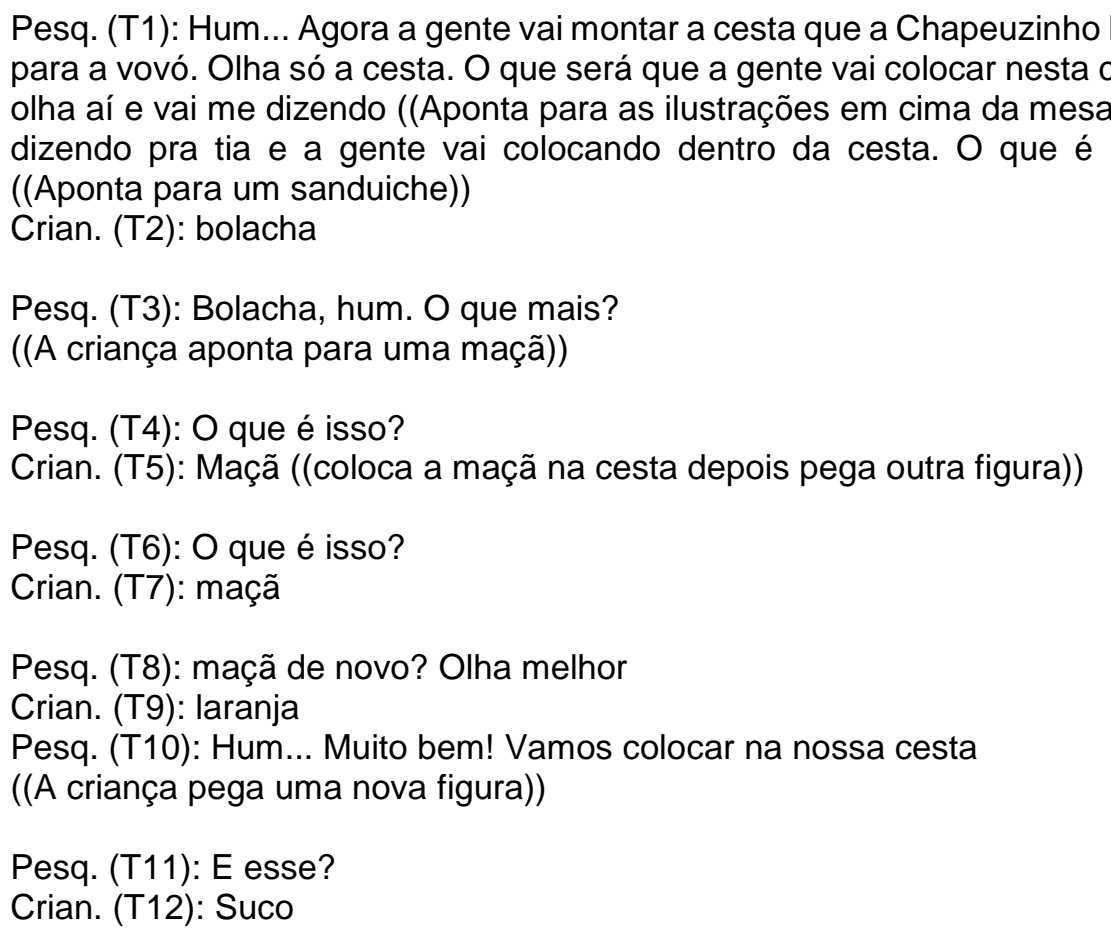

No exemplo 8 Laura produz uma frase completa, Eu "foi" pro parque, quando quer chamar a atenção da pesquisadora, quando é ela que inicia o diálogo, porém, quando é a pesquisadora que inicia, na maioria das vezes, como no exemplo 9, a criança responde com apenas uma palavra.

Conforme Duarte e Velloso (2017), as pessoas com DI sempre apresentam alterações no desenvolvimento no processo de comunicação, pois a capacidade de se comunicar através da linguagem é considerada uma tarefa muito complexa, porém, fundamental para o desenvolvimento pessoal ao longo da vida. E as pessoas com DI, mesmo possuindo algum potencial em nível de linguagem oral, desconhecem muitas vezes sua utilidade como ferramenta de comunicação.

Para as referidas autoras, os déficits relacionados à habilidade comunicativa constituem um dos maiores desafios na educação da pessoa com deficiência intelectual, pois podem apresentar escassa iniciativa nas interações, uso da linguagem de forma estereotipada e descontextualizada e escassa utilização da linguagem em suas diferentes funções.

\section{Considerações finais}


http://dx.doi.org/10.5902/1984686X39773

O resultado das avaliações de Ana e Laura aponta que o impedimento comunicativo de ambas as crianças pode não está centrado à função receptiva da linguagem, já que se identificou que na maioria das vezes as crianças demonstram compreender as falas dirigidas a elas, porém, como em alguns momentos Laura não responde a algumas perguntas considerou-se a possibilidade da criança ter alguma dificuldade para compreensão.

Já nos aspectos expressivos da linguagem, descartou-se impedimentos relacionados à execução motora da fala, tanto Ana como Laura conseguem dar "forma" ao som, e embora Ana apresente mais dificuldades em produzir palavras compreensíveis, não apresenta dificuldades auditivas ou articulatórias. Também no aspecto expressivo da linguagem, notou-se que as crianças, algumas vezes, davam respostas desconectadas ou demonstravam insegurança para responder aos questionamentos, o que pode estar relacionado ao modo como elas organizam as informações e elaboram as respostas, mais especificamente ao planejamento da fala.

Outro aspecto identificado da linguagem das crianças é em relação ao estímulo para interagir. No caso de Ana que possui pouca fala oral, apesar de, às vezes, não ter muito a atenção dos colegas, demonstrou por diversas vezes iniciativa para interagir. Já no caso de Laura, que possui fala oralizada, não houve muitos momentos em que a criança demonstrou interesse em iniciar ou participar de conversas com os colegas, e quando interage se distrai com facilidade, fazendo com que, às vezes, produza falas descontextualizadas.

Com a identificação dos aspectos da linguagem das crianças a partir da avaliação das habilidades comunicativas, elaborou-se um de plano de intervenção com o uso de recursos de CAA. Priorizou-se nas intervenções atividades dinâmicas para chamar a atenção da criança à interação.

Os achados desta pesquisa trazem uma discussão importante no que se refere à inclusão da criança com deficiência intelectual no âmbito escolar. Sabe-se que por muito tempo as pessoas com DI foram estigmatizadas como incapazes de aprender. A escola tradicional com suas práticas homogeneizadoras reforçava ainda mais a deficiência, excluindo essas crianças.

A pesquisa colabora com as discussões a respeito da inclusão escolar à medida que constata a necessidade de estratégias pedagógicas que permitam o desenvolvimento de todas as crianças, com ou sem deficiência. O que só é possível se ao olhar para a criança 
http://dx.doi.org/10.5902/1984686X39773

com deficiência se enxergue de suas capacidade e habilidades, não nas suas impossibilidades. Só valorizando o potencial das crianças que será possível visualizar os próximos passos para seu desenvolvimento.

Também que as ações interventivas com tecnologias assistivas, como o uso de comunicação alternativa, deve ser implantado desde cedo. A estimulação precoce pode fazer toda diferença no desenvolvimento das crianças com deficiência, pois como afirma Vygotski (1997, p. 117) o bom aprendizado é somente aquele que se adianta ao desenvolvimento.

No caso do desenvolvimento comunicativo, a pesquisa demonstrou que o uso de comunicação alternativa unida a atividades pedagógicas de estímulo à linguagem oral, ainda na Educação Infantil, podem potencializar a aquisição e desenvolvimento da linguagem das crianças com deficiência intelectual, o que, em sala de aula, pode permitir que as crianças com DI tenham tantas oportunidades de desenvolvimento quanto às demais crianças sem deficiência.

Como o debate sobre a educação inclusiva não se esgota, essa pesquisa traz outros questionamentos podendo ser a problemática de novas pesquisas. Dentre as inquietações, a principal foi a respeito das contribuições que o uso de comunicação alternativa pode proporcionar dentro da sala de aula, com intervenções que envolva não só a criança com impedimentos comunicativos, mas a participação de todas as crianças.

\section{Referências}

ANHÃO, Patrícia Páfaro Gomes; PFEIFER, Luiza lara; SANTOS, Jair Lício. Interação social de crianças com Síndrome de Down na Educação Infantil. Rev. Bras. Ed. Esp., Marília, v.16, n.1, p.31-46, Jan.-Abr, 2010.

BARDIN, Laurence. Análise de Conteúdo. Lisboa, Portugal: Edições 70, LDA, 2009.

BERGAMASCO, et al. Registro em vídeo na Pesquisa em psicologia: reflexões a partir de relatos de experiência. Revista Psicologia: Teoria e pesquisa. Set-Dez. Vol. 12 n.3 pp. 261-267 1996.

CAVALCANTE, Tícia Cassiany Ferro. Dialogismo e impedimentos cognitivos: reflexões sobre a comunicação entre adulto e estudantes com deficiência intelectual. Rev. educ. PUC-Camp., Campinas, 22(3):425-439, set./dez., 2017.

CAVALCANTE, Tícia Cassiany Ferro; FERREIRA, Sandra Patrícia Ataíde. Impedimentos cognitivos e a acessibilidade comunicacional na escola: contribuições da teoria de Vygotsky. Ciência \& Cognição, v.16, n.3, p.43-56, 2011. 
DE PAULA, Raquel. Desenvolvimento de um protocolo para avaliação de habilidades comunicativas de alunos não-falantes em ambiente escolar. 2007. Dissertação

(Mestrado em Educação) - Universidade Estadual Paulista, Faculdade de Filosofia e Ciências, 2007.

DELAGRACIA, Joyce Degaspari. Desenvolvimento de um protocolo para avaliação de habilidades comunicativas para alunos não-falantes em situação familiar. 2007.

Dissertação (Mestrado em Educação) - Universidade Estadual Paulista, Faculdade de Filosofia e Ciências, 2007.

DELIBERATO, Débora. Comunicação Alternativa na Educação Infantil: instrumentos para aquisição de competências do aluno com deficiência. In: D. DELIBERATO; D. NUNES; M. J. GONÇALVES (Orgs). Trilhando juntos a Comunicação Alternativa. Marília: ABPEE, 2017.

DUARTE, Cíntia Perez; VELLOSO, Renata de Lima. Linguagem e comunicação de pessoas com deficiência intelectual e suas contribuições para a construção da autonomia. Revista Inclusão Social. Brasília, DF, v.10 n.2, p.88-96, jan./jun. 2017.

FUJIHIRA, Carolina Yuki (Org.) Mude seu falar que eu mudo o meu ouvir: Acessibilidade: Um livro escrito por pessoas como Síndrome de Down. Associação Carpe Diem. São Paulo: Associação Carpe Diem, 2012.

LOURENÇO, Gerusa Ferreira. Sala de recursos multifuncionais e os desafios para a parceria com a sala comum nas práticas com tecnologia assistiva e comunicação alternativa e ampliada. In: D. DELIBERATO; D. NUNES, D; GONÇALVES, M. J. (Org). Trilhando juntos a Comunicação Alternativa. Marília: ABPEE, 2017.

LURIA, Alexander Romanovich. Pensamento e linguagem: as últimas conferencias de Luria. Porto Alegre: Artes Médicas, 1987.

MANZINI, Eduardo José; DELIBERATO, Débora. Recursos para a comunicação alternativa. BRASIL. Portal de ajudas técnicas para a Educação: Equipamento e material pedagógico para a educação capacitação e recreação da pessoa com deficiência física. Secretaria de Educação Especial, Brasília - MEC: SEES, 2004.

MARCUSCHI, Antônio. Análise da Conversação. São Paulo: Editora Ática, 2000.

NUNES, Leila Regina Oliveira de Paula. Favorecendo o desenvolvimento da comunicação em jovens com necessidades educacionais especiais. Rio de Janeiro: Dunya, 2003.

PASSERINO, Liliana Maria; BEZ, Maria Rosângela. Comunicação Alternativa: Mediação para uma inclusão social a partir do Scala. Passo Fundo: Ed. Universitária de Passo Fundo, 2015.

REILY, Lucia. Escola Inclusiva: Linguagem e mediação (Série Educação Especial). Campinas, São Paulo: Papirus, 2004. 
http://dx.doi.org/10.5902/1984686X39773

SANTOS, Daísy Cléia Oliveira dos. Potenciais dificuldades e facilidades na educação de alunos com deficiência intelectual. Revista Educação e Pesquisa. São Paulo, v. 38, p. 935-948, out/dez, 2012.

SARTORETTO, Mara Lúcia; BERSCH, Rita. Comunicação Alternativa. 2014. Disponível em: http://www.assistiva.com.br/ca.html. Acessado em: 20 de janeiro de 2015.

SCARPA, Ester Miriam. Aquisição da linguagem. In: A. C. BENTES; F. MUSSALIM (Orgs.) Introdução à linguística 2: domínios e fronteiras. São Paulo: Cortez, 2001. p. 203-232.

TETZCHNER, Stephen Von; MARTINSEN, Harald. Introdução à comunicação aumentativa e Alternativa. Porto: Porto Editora, 2000.

VIANNA, Heraldo Marelim. Pesquisa em educação: a observação. Liber Livro Editora Ltda. Brasília, DF. 2003.

VYGOTSKI, Lev Semyonovich. Obras escogidas V: fundamentos da defectologia. Madrid: Visor, 1997.

VYGOTSKI, Lev Semyonovich. A Construção do Pensamento e da Linguagem. São Paulo: Martins Fontes, 2001.

\section{Correspondência}

Cristiane Makida Dyonisio - Universidade Federal de Pernambuco, Centro de Educação, Av. Professor Moraes Rego, Cidade Universitária, Recife, Pernambuco, Brasil.

CEP: $50670-901$

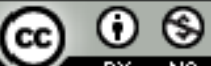

EY This work is licensed under a Creative Commons Attribution-NonCommercial

4.0 International (CC BY-NC 4.0) 